\title{
Malignant Struma Ovarii with Concurrent Thyroid Cancer: Outcomes during and after Pregnancy
}

\author{
Sara Donato ${ }^{a}$ Helder Simões $^{a, b}$ Valeriano Leite ${ }^{a, b, c}$

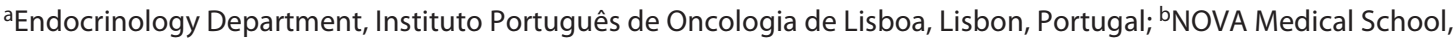 \\ Faculdade de Ciências Médicas, Universidade Nova de Lisboa, Lisbon, Portugal; ' Unidade de Investigação em \\ Patobiologia Molecular, Instituto Português de Oncologia de Lisboa, Lisbon, Portugal
}

\section{Established Facts}

- Struma ovarii (SO) is a rare ovarian teratoma characterized by the presence of thyroid tissue that can undergo malignant transformation;

- Patients with malignant SO seem to present a more aggressive form of disease than differentiated thyroid cancer;

- There are scarce data about malignant SO evolution during pregnancy.

\section{Novel Insight}

- Pregnancy may represent a stimulus for malignant SO growth in patients with previous biochemical evidence of disease.

\section{Keywords}

Struma ovarii · Thyroid cancer · Pregnancy

\begin{abstract}
Introduction: Struma ovarii (SO) is a rare ovarian teratoma characterized by the presence of thyroid tissue in more than $50 \%$ of the tumor. Malignant transformation is rare and the most common associated malignancy is papillary thyroid carcinoma (PTC). Pregnancy may represent a stimulus to differentiated thyroid cancer (DTC) growth in patients with known structural or biochemical evidence of disease, but data about malignant SO evolution during pregnancy are
\end{abstract}

rare. We present the first reported case of a pregnant patient with malignant SO and biochemical evidence of disease. Case Presentation: A previously healthy 35-year-old female diagnosed with a suspicious left pelvic mass on routine ultrasound was submitted to laparoscopic oophorectomy which revealed a malignant SO with areas of PTC. A 15- $\mathrm{mm}$ thyroid nodule (Bethesda $\mathrm{V}$ in the fine-needle aspiration cytology) was detected by palpation and total thyroidectomy was performed. Histology revealed a $15 \mathrm{~mm}$ follicular variant of PTC (T1bNxMx). Subsequently, she received $100 \mathrm{mCi}$ of radioactive iodine therapy (RAIT) with the whole-body scan showing only moderate neck uptake. Her suppressed thyroglobulin (Tg) before RAI was $1.1 \mathrm{ng} / \mathrm{mL}$. She maintained bio- 
chemical evidence of disease, with serum Tg levels of $7.6 \mathrm{ng} /$ $\mathrm{mL}$. She got pregnant 14 months after RAIT, and during pregnancy, Tg increased to $21.5 \mathrm{ng} / \mathrm{mL}$. After delivery, Tg decreased to $14 \mathrm{ng} / \mathrm{mL}$ but, 6 months later, rose again and reached $31.9 \mathrm{ng} / \mathrm{mL}$ on the last follow-up visit. TSH was always suppressed during follow-up. At the time of SO diagnosis, a chest computed tomography scan showed 4 bilateral lung micronodules in the upper lobes which were nonspecific, and 9 months after diagnosis, a pelvic MRI revealed a suspicious cystic nodule located on the oophorectomy bed. These lung and pelvic nodules remained stable during follow-up. Neck ultrasonography, abdominal MRI, and fluorodeoxyglucose-positron emission tomography showed no suspicious lesions. Discussion/Conclusion: As for DTC, pregnancy seems to represent a stimulus to malignant SO growth. This can be caused by the high levels of estrogen during pregnancy that may bind to receptors in malignant cells and/or by the high levels of hCG which is known to stimulate TSH receptors.

(C) 2021 European Thyroid Association Published by S. Karger AG, Basel

\section{Introduction}

Struma ovarii $(\mathrm{SO})$ is a rare ovarian teratoma $(2-5 \%$ of all teratomas) characterized by the presence of thyroid tissue in more than $50 \%$ of the tumor [1-5]. Malignant transformation is rare (about $0.1-5 \%$ of the cases) and is defined by the same histological criteria as for thyroid cancer [2-5]. Metastatic malignant SO has been described to occur in 5-6\% of the cases, and metastases are usually located within the abdomen [2]. The most common malignancy in $\mathrm{SO}$ is papillary thyroid carcinoma (PTC) [4]. Literature concerning this topic is scarce, and treatment is controversial [1-5]. The coexistence of differentiated thyroid cancer (DTC) and malignant SO in the same patient is an exceptional finding in clinical practice and reasons for such an association are unknown [6]. Most of the existing data about malignant SO during pregnancy refer to its diagnosis during this condition $[5,7]$. Only 1 published paper was found describing the occurrence of pregnancy following malignant SO treatment but in a patient without evidence of disease [7]. Since we know that pregnancy may represent a stimulus to thyroid cancer growth in patients with DTC, with known structural or biochemical evidence of disease [8], it is worth describing the behavior of malignant $\mathrm{SO}$ in a patient with biochemical evidence of disease during pregnancy which is, as far as we know, the first such case reported in the literature.

\section{Case Report}

A previously healthy 35-year-old multipara (gravida 3, para 3) was diagnosed with a suspicious left pelvic mass in a routine ultrasound (US) performed in 2015, after the birth of the second son. The lesion was heterogeneous, predominantly cystic and multilocular measuring $82 \mathrm{~mm}$ of maximal dimension, with an internal ill-defined area. She was asymptomatic and there was no clinical evidence of thyroid dysfunction, ascites, hydrothorax, or pain. CA 125 and alpha-fetoprotein serum levels were within the normal range. Since she wished to preserve fertility, a left laparoscopic oophorectomy was performed in another institution. In the surgical description there was no reference to the right ovary. Histology revealed an ovarian teratoma measuring $70 \mathrm{~mm}$, with $95 \%$ of the area occupied by a malignant struma ovarii (SO) with a follicular variant of PTC (without vascular invasion or extra-ovarian extension) and $5 \%$ of the remaining mass occupied by squamous ectodermal tissue. Surgical limits were free, but there was intra-operatory fragmentation of the piece. The BRAF V600E mutation was not found in the malignant SO tissue. The postoperative period was uneventful.

Following the malignant SO diagnosis, the patient was referred to the endocrine department, and on the neck examination, a 1.5 $\mathrm{cm}$ firm nodule in the thyroid gland was disclosed. The US identified a solid isocogenic nodule of $17 \times 18 \times 8 \mathrm{~mm}$, EU-TIRADS 3 [9], and the US-guided fine-needle aspiration biopsy diagnosis was suspicious for malignancy (Bethesda V [10]). She was then submitted to a total thyroidectomy. A 15-mm follicular variant of PTC (T1bNxMx), without vascular invasion or extra-thyroidal extension, was found and she was started on levothyroxine suppressive treatment. Chest computed tomography (CT) scan detected 4 bilateral lung micronodules in the upper lobes with $4 \mathrm{~mm}$ of maximal dimension which were considered as nonspecific (one of the nodules shown in Fig. 1), and a fluorodeoxyglucose-positron emission tomography CT scan showed no evidence of uptake suggestive of malignant tissue. Her suppressed serum thyroglobulin (Tg) 2 months after surgery was $1.1 \mathrm{ng} / \mathrm{mL}$ (functional sensitivity of 0.9 $\mathrm{ng} / \mathrm{mL}$ and an analytical sensitivity of $0.2 \mathrm{ng} / \mathrm{mL}$ ).

She received $100 \mathrm{mCi}$ of radioactive iodine (RAI) with recombinant TSH. The stimulated Tg was $7.5 \mathrm{ng} / \mathrm{mL}$ and the post-RAI whole-body scan showed a moderate cervical residual uptake (as presented in Fig. 1). There was no pelvic uptake of RAI.

During follow-up, progressive biochemical evidence of disease (Tg increased from $2.5 \mathrm{ng} / \mathrm{mL}$ to $7.6 \mathrm{ng} / \mathrm{mL}$ ) was documented. Neck US did not show any suspicious findings and a pelvic MRI detected a cystic lesion measuring $12 \times 7 \mathrm{~mm}$ in the oophorectomy bed (shown in Fig. 1).

She got pregnant at the age of 37 , and during pregnancy, $\mathrm{Tg}$ increased further to $21.5 \mathrm{ng} / \mathrm{mL}$ at the 20 th week. TSH was kept $<0.1 \mathrm{mUI} / \mathrm{L}$ (reference range: $0.30-4.20 \mathrm{mUI} / \mathrm{L}$ ) during pregnancy in accordance with recommendations for DTC with disease persistence [8]. Clinically, she remained asymptomatic with no evidence of structural progression of disease. No complications occurred during pregnancy and a healthy male child was born at 40 weeks.

One month after delivery, suppressed serum Tg level was $14 \mathrm{ng} /$ $\mathrm{mL}$. On the last observation (5 years after diagnosis), she was asymptomatic and had a serum $\mathrm{Tg}$ of $31.9 \mathrm{ng} / \mathrm{mL}$ with a TSH $<0.02$ $\mathrm{mUI} / \mathrm{L}$. Cervical US did not reveal any suspicious nodules and the cystic nodule identified in the oophorectomy bed, as well as the 

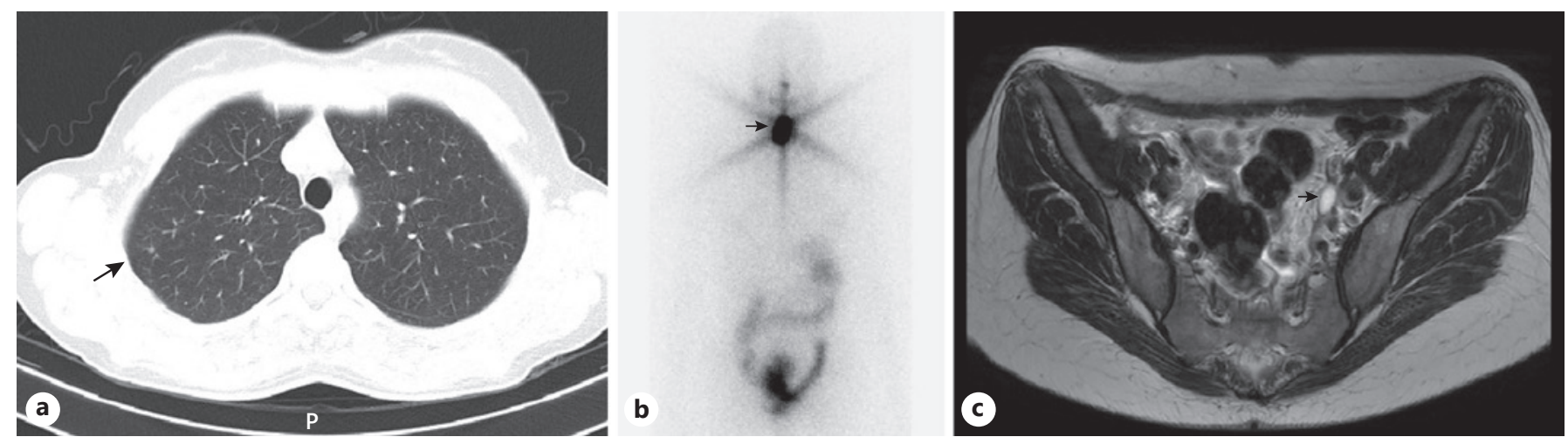

Fig. 1. One of the nonspecific lung nodules shown in the chest CT scan (arrow) (a); Post-RAI WBS showing moderate residual neck uptake (arrow), physiological uptake in the bowel and bladder (b); Cystic lesion in the oophorectomy bed shown in a T2-weighted MRI image (arrow) (c). CT, computed tomography; RAI, radioactive iodine; WBS, whole-body scan.

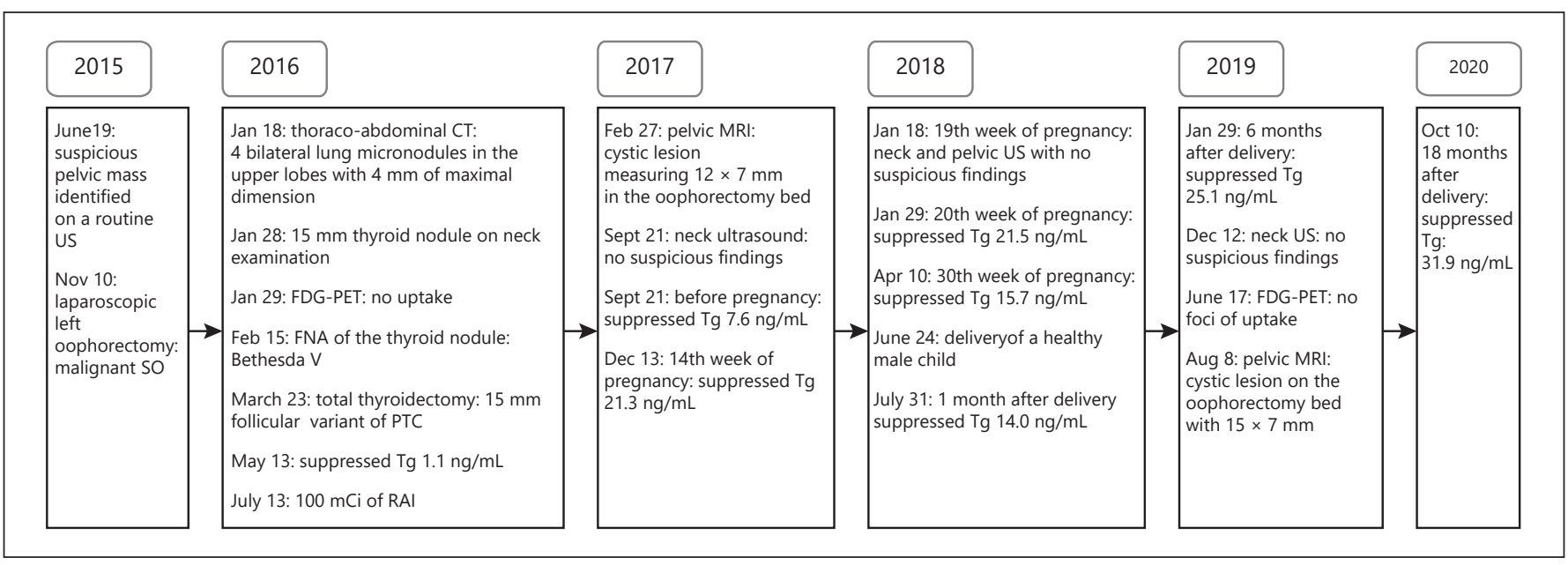

Fig. 2. Timeline of events. US, ultrasound; SO, struma ovarii; CT, computed tomography; FDG-PET, fluorodeoxyglucose-positron emission tomography; FNA, fine-needle aspiration; PTC, papillary thyroid cancer; Tg, thyroglobulin.

lung micronodules, have remained stable. A fluorodeoxyglucosepositron emission tomography TC scan was also performed and did not show any suspicious foci of uptake. Her child is now almost 2 years old and healthy. In Figure 2 a timeline of the case is presented, and in Table 1 the evolution of serum Tg levels during follow-up is shown.

\section{Discussion/Conclusion}

It is known that pregnancy may represent a stimulus for DTC growth in patients with structural or biochemical evidence of disease [8], possibly due to the high levels of estrogen that occur during that physiological state, which can bind to receptors present in cancer cells [5]. Also, hCG is known to stimulate TSH receptors and may promote tumor growth during pregnancy [5]. Functional TSH receptors were previously found in the mature human granulosa cells, suggesting that TSH receptors may participate in the regulation of ovarian function. In this case, this might also act as a stimulus for the malignant SO growth [11]. The behavior of malignant SO in this scenario remains unknown. In the present case, we observed that serum Tg levels increased during the first half of the pregnancy with reduction in late pregnancy and in 
Table 1. Serum Tg evolution during follow-up

\begin{tabular}{|c|c|c|c|c|c|c|c|c|c|c|}
\hline Date & $\begin{array}{l}13 \text { May } 2016 \\
\text { after TT and } \\
\text { oophor }\end{array}$ & $\begin{array}{l}13 \mathrm{Jul} 2016 \\
\text { RAI therapy }\end{array}$ & 11 Nov 2016 & $\begin{array}{l}21 \text { Sep } 2017 \\
\text { before } \\
\text { pregnancy }\end{array}$ & $\begin{array}{l}13 \text { Dec } 12 \\
1714 \text { th wk of } \\
\text { pregnancy }\end{array}$ & $\begin{array}{l}29 \text { Jan } 2018 \\
20 \text { th wk of } \\
\text { pregnancy }\end{array}$ & $\begin{array}{l}10 \text { Apr } 2018 \\
\text { 30th wk of } \\
\text { pregnancy }\end{array}$ & $\begin{array}{l}31 \mathrm{Jul} 2018 \\
1 \mathrm{mo} \text { after } \\
\text { delivery }\end{array}$ & $\begin{array}{l}29 \text { Jan } 2019 \\
6 \text { mos after } \\
\text { delivery }\end{array}$ & $\begin{array}{l}10 \text { Feb } 20 \\
18 \text { mos after } \\
\text { delivery }\end{array}$ \\
\hline TSH, mUI/L & 0.11 & $>100$ & 0.06 & 0.02 & 0.02 & 0.04 & 0.03 & $<0.02$ & $<0.02$ & $<0.02$ \\
\hline $\mathrm{AA}-\mathrm{Tg}, \mathrm{UI} / \mathrm{mL}$ & $<280$ & $<280$ & $<280$ & $<280$ & $<280$ & $<280$ & $<280$ & $<280$ & $<280$ & $<280$ \\
\hline
\end{tabular}

Tg, thyroglobulin; TSH, thyroid-stimulating hormone; AA-Tg, anti-thyroglobulin antibodies; TT, total thyroidectomy; oophor, oophorectomy; RAI, radioactive iodine; wk, week; mo(s), month(s). Tg functional sensitivity, $0.9 \mathrm{ng} / \mathrm{mL} ; \mathrm{Tg}$ analytical sensitivity, $0.2 \mathrm{ng} / \mathrm{mL}$; TSH normal range, $0.30-4.20 \mathrm{mUI} / \mathrm{L}$; AA-Tg negative, $<280 \mathrm{UI} / \mathrm{mL}$.

the postdelivery period sustaining the hypothesis that the pregnant state favors the growth of malignant thyroid tissue of ovarian origin.

The coexistence of DTC and malignant SO in the same patient is very rare $[6,12]$. In a retrospective analysis of the SEER database, DTC was found in 2 patients out of the 21 that had malignant SO [12]. Most likely, they represent synchronous separate primary tumors, and not an ovarian metastasis of a thyroid tumor, since this tissue is a rare metastatic site of DTC spread $[6,13]$. The histopathological characteristics of the tumors may help to differentiate them [6]. In our case both tumors showed features of PTC with a follicular pattern, but the malignant $\mathrm{SO}$ also had features of teratoma with squamous ectodermal tissue that would not be present if this was a metastasis. All these features favor the synchronous occurrence of the 2 tumors in our case.

There are some factors that have been associated with increased risk of aggressive behavior in malignant SO such as struma size greater than $5 \mathrm{~cm}$, presence of more than $50 \%$ of proliferating tissue within a teratoma, extra-ovarian spread, adherence to adjacent organs, ascites, age over 55 years, and FIGO (International Federation of Gynecology and Obstetrics) stage IV of ovarian cancer $[2,4,14]$. The first 2 were present in our case. Also, the intraoperative fragmentation might have contributed to tumor persistence because serum Tg levels were high and a cystic lesion was detected on the left oophorectomy bed. Although nonspecific, the small nodules observed in lungs, may represent distant metastatic spreading, probably from the pelvic tumor, rather than a DTC origin, due to intraoperative fragmentation of the surgical piece. It is important to mention that both the pelvic lesion and the lung micronodules did not show FDG uptake; however, this does not exclude slow growing malignant disease. We favor the hypoth- esis that, during pregnancy, the increase in serum $\mathrm{Tg}$ levels were due to malignant SO growth rather than PTC growth since the first tumor had high-risk features and was intraoperatively fragmented.

We could hypothesize that pelvic uptake on the postRAI WBS was hidden by the thyroid bed uptake but it seems not to be the case since the activity of $131 \mathrm{I}$ administered was relatively high $(100 \mathrm{mCi})$ and the neck uptake was not intense. A SPECT-CT, if performed, could have increased the sensitivity of the study. However, nonstimulated serum Tg levels at that time were very low $(1.1 \mathrm{ng} / \mathrm{mL})$ reflecting the presence of minimal residual disease.

This is the first reported case of a malignant SO with concurrent DTC and biochemical evidence of disease progression during pregnancy, which could be caused by the high levels of estrogen that may bind to receptors in malignant cells and/or by the high levels of hCG which is known to stimulate TSH receptors.

\section{Statement of Ethics}

This patient has given her written informed consent to publish her case. This study complies with the World Medical Association Declaration of Helsinki.

\section{Conflict of Interest Statement}

The authors have no conflicts of interest to declare.

\section{Funding Sources}

There were no funding sources to this study. 


\section{Author Contributions}

Sara Donato was responsible for the acquisition, analysis, and interpretation of data for the work; drafting it; final approval of the version to be published and agree to be accountable for all as- pects of the paper. Helder Simões and Valeriano Leite were responsible for the interpretation of data for the work, revising it critically for important intellectual content, final approval of the version to be published and agree to be accountable for all aspects of the paper.

\section{References}

1 Goffredo P, Sawka AM, Pura J, Adam MA, Roman SA, Sosa JA. Malignant struma ovarii: a population-level analysis of a large series of 68 patients. Thyroid. 2015 Feb;25(2):211-5.

2 Gonzalez Aguilera B, Guerrero Vazquez R, Gros Herguido N, Sanchez Gallego F, Navarro Gonzalez E. The lack of consensus in management of malignant struma ovarii. Gynecol Endocrinol. 2015 April;31(4):258-9.

3 Gobitti C, Sindoni A, Bampo C, Baresic T, Giorda G, Alessandrini L, et al. Malignant struma ovarii harboring a unique NRAS mutation: case report and review of the literature. Hormones. 2017 Jul;16(3):322-7.

4 Oudoux A, Leblanc E, Beaujot J, GauthierKolesnikov H. Treatment and follow-up of malignant struma ovarii: regarding two cases. Gynecol Oncol Rep. 2016 Jun;17:56-9.

5 Lager CJ, Koenig RJ, Lieberman RW, Avram AM. Rare clinical entity: metastatic malignant struma ovarii diagnosed during pregnancy: lessons for management. Clin Diabetes Endocrinol. 2018 Jun; 4:13.
6 Fernández Catalina P, Rego Iraeta A, Lorenzo Solar M, Sánchez Sobrino P. Estruma ovárico maligno y cáncer papilar de tiroides sincrónicos. Endocrinol Nutr. 2016 Aug-Sep;63(7): 366-7.

7 Ihalagama IR, Hewavisenthi SJ, Wijesinghe PS. Pregnancy following treated malignant struma ovarii. Ceylon Med J. 2004 Sep;49(3): 90-1.

8 Alexander EK, Pearce EN, Brent GA, Brown RS, Chen H, Dosiou C, et al. 2017 guidelines of the american thyroid association for the diagnosis and management of thyroid disease during pregnancy and the postpartum. Thyroid. 2017 Mar;27(3):315-89.

9 Russ G, Bonnema SJ, Erdogan MF, Durante C, Ngu R, Leenhardt L. European thyroid association guidelines for ultrasound malignancy risk stratification of thyroid nodules in adults: the EU-TIRADS. Eur Thyroid J. 2017 Sep;6(5):225-37.
10 Cibas ES, Ali SZ. The 2017 bethesda system for reporting thyroid cytopathology. Thyroid. 2017 Nov;27(11):1341-6.

11 Sun SC, Hsu PJ, Wu FJ, Li SH, Lu CH, Luo CW. Thyrostimulin, but not thyroid-stimulating hormone (TSH), acts as a paracrine regulator to activate the TSH receptor in mammalian ovary. J Biol Chem. 2010 Feb;285(6): 3758-65.

12 Sisti A, Tassinari J, Nisi G, Grimaldi L, Sisti G, Di Tommaso M, et al. Synchronous and metachronous malignancies after malignant struma ovarii in the SEER database. In vivo. 2016 Sep;30(5):713-6.

13 Brogioni S, Viacava P, Tomisti L, Martino E, Macchia E. A special case of bilateral ovarian metastases in a woman with papillary carcinoma of the thyroid. Exp Clin Endocrinol Diabetes. 2007 Jun;115(6):397-400.

14 Sijian Li S, Yang T, Li X, Zhang L, Shi H, Cheng N, et al. FIGO stage IV and age over 55 years as prognostic predicators in patients with metastatic malignant struma ovarii. Front Oncol. 2020. 